\title{
A study on the effects of graphene nano-platelets (GnPs) sheet sizes from a few to hundred microns on the thermal, mechanical, and electrical properties of polypropylene (PP)/GnPs composites
}

\author{
Y-S. Jun, J. G. Um, G. Jiang, A. Yu* \\ Department of Chemical Engineering, University of Waterloo, 200 University Avenue West, N2L 3G1 Waterloo, Ontario, \\ Canada
}

Received 5 March 2018; accepted in revised form 16 May 2018

\begin{abstract}
Polypropylene (PP) is incorporated with four different grades (H100, M25, M5, and C300) of graphene nanoplatelets (GnPs) via twin screw extrusion followed by injection moulding. The composites' thermal stability, crystallization behaviour, tensile strength, and electrical property are carefully examined. The thermal stability is significantly enhanced with the incorporation of small-sized GnPs as shown by the $11.2 \%$ improvement in $T_{5 \%}$ (the temperature at which $5 \mathrm{wt} \%$ of the mass loss occurs) and $5.1 \%$ improvement in $T_{\max }$ (the temperature at which the maximum loss rate occurs). The thermal stabilizing effect of fillers can be significantly enhanced when they are well distributed with less aggregation as is the case for small-sized GnPs. The GnPs show a considerable nucleating effect on PP by increasing the crystallization temperature $\left(T_{\mathrm{c}}\right)$. The greatest improvement in tensile property is achieved with the use of small-sized GnPs. A $33.0 \%$ enhancement in tensile strength and 59.1\% improvement of tensile modulus are obtained with the use of C300 and M5, respectively. The significantly increased thermal stability and mechanical property with small-sized GnPs are due to the fact that these smallsized fillers achieve a high degree of dispersion with less agglomeration as shown in the scanning electron microscope (SEM) images. However, the fillers with a large sheet size are still beneficial for purposes concerning electrical conductivity since the lowest percolation is obtained with H100. The greater the size of the GnPs, the smaller the percolation threshold of composites is exhibited.
\end{abstract}

Keywords: polymer composites, polypropylene, graphene nano-platelets, electrical conductivity, tensile property

\section{Introduction}

Graphene is a single layer of carbon atoms packed in a honeycomb structure [1]. Upon the discovery of free standing graphene in 2004 , a revolutionary amount of research has been conducted to fully exploit the exceptional properties of graphene [2-9]. However, it has been considered extremely challenging to commercialize advanced products fabricated with graphene due to inability in mass production of high-quality graphene at low cost. Recently, graphene nano-platelets ( $\mathrm{GnPs}$ ) have been recognized as an inexpensive alternative to graphene due to its possibility of mass production at low cost $[10,11]$. GnPs are layered graphene nano-crystals in the structure of platelets stacked by van der Waal's forces [12]. The incorporation of GnPs into conventional polyolefins has promising potential in a vast array of applications due to its excellent thermal, mechanical, and electrical properties. Such composites can be employed in the fields of electronics, automobile, aerospace, sensors, and many more [13, 14]. Among many polymers, polypropylene (PP) is one of the 
most widely used thermoplastics owing to its great physical and mechanical properties, chemical resistance, recyclability, high processability, and low cost [15]. The field of applications for PP includes packaging, textiles (ropes and carpets), automotive components, etc. [16].

Due to the high potential of the PP composites incorporated with GnPs, researchers have extensively studied the various properties of the composites [1720]. It was revealed that the performance of the composites is highly dependent upon the physical characteristics of GnPs. For example, Liang et al. [17] showed that the tensile modulus of neat PP $(1.25 \mathrm{GPa})$ was $100 \%$ improved and reached up to $2.5 \mathrm{GPa}$ with the use of GnPs with diameters less than 10 microns and thickness smaller than $5 \mathrm{~nm}$. However, less reinforcement was achieved (tensile modulus reached $1.9 \mathrm{GPa}$ ) when greater-sized GnPs (with a diameter between 10 and 50 microns and thickness between 3.4 and $7 \mathrm{~nm}$ ) was employed. Kalaitzidou et al. [21] revealed that neat $\mathrm{PP}$ with initial flexural modulus of $\sim 1.2 \mathrm{GPa}$ reached a flexural modulus of $9 \mathrm{GPa}$ with the addition of $20 \mathrm{vol} \% \mathrm{GnPs}$ with a diameter of $1 \mu \mathrm{m}$ whereas $5 \mathrm{GPa}$ was obtained when $5 \mu \mathrm{m}$ diameter GnPs were used. Chunhui et al. [22] also revealed that the flexural strength is inversely proportional to the size of graphite. The incorporation of GnPs also significantly influences the thermal properties of polymeric materials. For instance, Bafana et al. [23] demonstrated that the addition of $1.5 \mathrm{wt} \%$ of GnPs increased $T_{10 \%}$ (temperature for $10 \%$ weight loss) by $29^{\circ} \mathrm{C}$. The crystallization behaviour of polymer matrix is also influenced when GnPs are present. For example, Pedrazzoli et al. [24] showed that the crystallization rate of the $\mathrm{PP} / \mathrm{GnPs}$ was increased by $380 \%$ with an amount of $0.01 \mathrm{wt} \%$ of GnPs during isothermal crystallization at $145^{\circ} \mathrm{C}$. They also reported that the growth of $\beta$-crystals of $\mathrm{PP}$ was promoted up to $11 \%$ with an amount of $1 \mathrm{wt} \%$ of GnPs. However, the studies that compare and reveal the relation between the GnPs sheet size and thermal properties are rather sparse. Moreover, the percolation threshold of $\mathrm{PP} / \mathrm{GnPs}$ composites is also closely associated with the sheet size of GnPs. Park et al. [25] showed that the exfoliated graphite nanoplatelets with sheet size of 1 micron gave a percolation threshold of $15 \mathrm{wt} \%$. It was also reported that the use of GnPs with 5 and $10 \mu \mathrm{m}$ in the diameter exhibited a percolation threshold of 6 and 4 vol\%, respectively [26].
As described above, when GnPs are incorporated, a variety of properties are improved, and this improvement is significantly dependent upon the sheet size of GnPs. Therefore, the size of GnPs should be carefully chosen to maximize the performance. For instance, relatively small sized GnPs should be incorporated when lightweight GnPs-reinforced composites are considered for automotive parts for an improved fuel economy in the future. GnPs can also be utilized for high barrier performance packaging materials for chemical, solvent, and fuel containers. For safety issues, relatively large sized GnPs can used to improve electrical conductivity for prevention of electrostatic discharge. Therefore, it is essential to understand the effects of the GnPs' physical properties on the performance of the composites from a manufacturing point of view when the composites are fabricated via conventional industrial machines. However, few studies systematically investigate the influences of a wide range of the GnPs' sheet size spanning from a few to hundreds of microns on the various properties of the composites. Hence the objectives of this study were to investigate the effects of physical property of GnPs on the thermal stability, crystallization behaviour of PP, tensile strength, and electrical conductivity of $\mathrm{PP} / \mathrm{GnPs}$ composites. The size of the GnPs used in this study spanned from a few microns to several hundred microns in diameter. Several physical properties, such as the number of particles per unit volume and surface area, vary with the GnPs' sheet size and therefore will also be considered when discussing various properties of the composites.

\section{Materials and methods}

\subsection{Materials}

PP (HM20/70P) was obtained from Goonvean Fibres Ltd. and used as received. The average size of this powder type PP for this grade falls in a range of 0.055 to $0.077 \mathrm{~mm}$ with a density of 0.90 to $0.91 \mathrm{~g} / \mathrm{cm}^{-3}$. The melt flow index was measured to be $19.4 \mathrm{~g} / 10 \mathrm{~min}$ at $230^{\circ} \mathrm{C}$ and $2.16 \mathrm{~kg}$ (D4002, Dynisco Polymer Test

Table 1. Dimensions and physical properties of GnPs used in this study. These values were provided in the technical sheet from XG science.

\begin{tabular}{|ll|c|c|c|c|}
\hline \multicolumn{2}{|c|}{ Grades of GnPs } & H100 & M25 & M5 & C300 \\
\hline Diameter & {$[\mu \mathrm{m}]$} & $>150$ & $>25$ & $>5$ & $>2$ \\
\hline Thickness & {$[\mathrm{nm}]$} & $\sim 15$ & $\sim 6-8$ & $\sim 6-8$ & $\sim 5$ \\
\hline Surface area & {$\left[\mathrm{m}^{2} / \mathrm{g}\right]$} & $50-80$ & $120-150$ & $120-150$ & $\sim 300$ \\
\hline
\end{tabular}



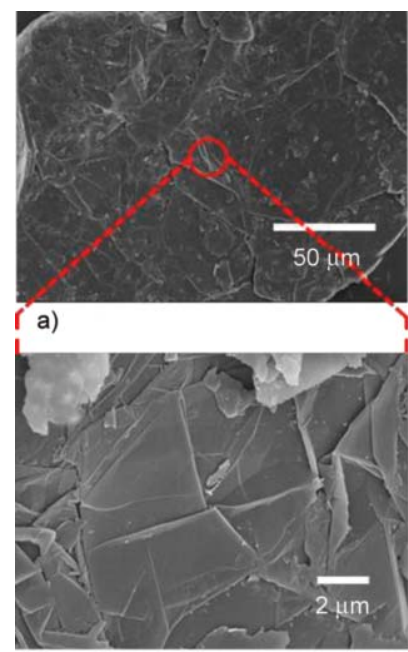

e)

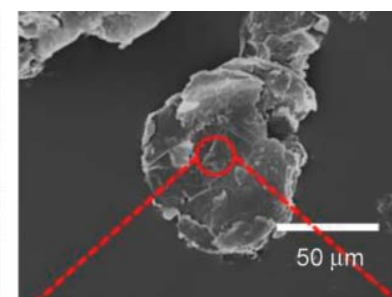

(b)

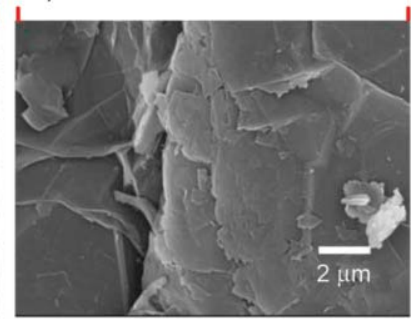

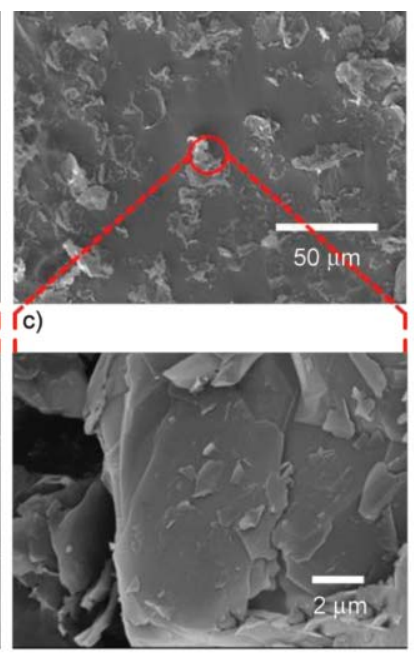

g)

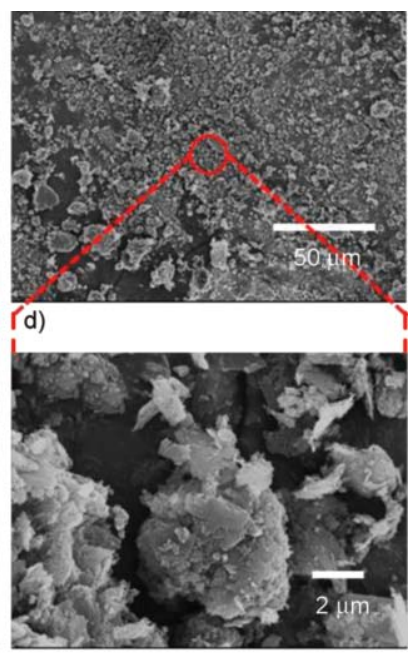

h)

Figure 1. The SEM images of GnPs for each grade: (a and e) H100, (b and f) M25, (c and g) M5, and (d and h) C300.

Systems). Three different grades (Grade M, C, and $\mathrm{H})$ of GnPs and two different sizes of grade M (5 and $25 \mu \mathrm{m})$ were purchased from XG Science. The dimensions and physical properties of GnPs were determined and detailed in Table 1. The SEM images of each grade of the GnPs are provided in Figure 1.

\subsection{Composites preparation}

PP was compounded with grade M25, M5, and C300 GnPs with desired mass fractions ranging from 5 to $20 \mathrm{wt} \%$. The mass fraction was converted to volume fraction, and the compositions of all the samples are summarized in Table 2. The data for PP composites with $\mathrm{H} 100$ was reproduced from our previous study [27]. Both PP and GnPs were suspended in ethanol and mechanically stirred for an improved dispersion. The mixture was dried in a vacuum oven at $60^{\circ} \mathrm{C}$ for 24 hours and fed into the counter-rotating conical micro-compounder (Ruiming, SJZS-07A). The temperature setting from the hopper to the die was $165 / 170 / 175 / 185$. The mixture of PP and GnPs was circulated for $5 \mathrm{~min}$ and extruded. The screw speed was $24 \mathrm{rpm}$. The compounded strands were pelletized by a pelletizing machine and desiccated again at $60^{\circ} \mathrm{C}$ for 12 hours to avoid moisture inclusion. The dried and pelletized extrudates were then added into an injection moulding machine.

\subsection{Characterizations}

\subsubsection{Thermal behaviour and stability}

The thermal behaviour of the PP/GnPs composites were examined by means of differential scanning calorimeter (DSC) using a thermal analyser (TA
Table 2. Summary of composite compositions and corresponding volume percent.

\begin{tabular}{|c|c|c|c|}
\hline \multicolumn{2}{|c|}{ Filler } & \multicolumn{2}{|c|}{ PP } \\
\hline [wt\%] & [vol\%] & {$[w t \%]$} & [vol\%] \\
\hline \multicolumn{4}{|c|}{ H100 } \\
\hline 0.0 & 0.0 & 100.0 & 100.0 \\
\hline 3.0 & 1.3 & 97.0 & 98.7 \\
\hline 7.5 & 3.2 & 92.5 & 96.8 \\
\hline 10.0 & 4.4 & 90.0 & 95.6 \\
\hline 20.0 & 9.3 & 80.0 & 90.7 \\
\hline \multicolumn{4}{|c|}{ M25 } \\
\hline 5.0 & 2.1 & 95.0 & 97.8 \\
\hline 10.0 & 4.4 & 90.0 & 95.6 \\
\hline 15.0 & 6.7 & 85.0 & 93.3 \\
\hline 20.0 & 9.3 & 80.0 & 90.7 \\
\hline \multicolumn{4}{|c|}{ M5 } \\
\hline 5.0 & 2.1 & 95.0 & 97.8 \\
\hline 10.0 & 4.4 & 90.0 & 95.6 \\
\hline 15.0 & 6.7 & 85.0 & 93.3 \\
\hline 20.0 & 9.3 & 80.0 & 90.7 \\
\hline \multicolumn{4}{|c|}{ C300 } \\
\hline 5.0 & 2.1 & 95.0 & 97.8 \\
\hline 10.0 & 4.4 & 90.0 & 95.6 \\
\hline 15.0 & 6.7 & 85.0 & 93.3 \\
\hline 20.0 & 9.3 & 80.0 & 90.7 \\
\hline
\end{tabular}

Q2000, USA). The samples were scanned from -30 to $250^{\circ} \mathrm{C}$ under nitrogen atmosphere with ramping rates of $10^{\circ} \mathrm{C} /$ minute. The specimens were treated at $250^{\circ} \mathrm{C}$ for 3 minutes to eliminate the thermal history. The thermal stability was studied by means of thermogravimetric analysis (TGA) using a thermal analyser (TA Q500, USA). The samples were treated from 20 to $800^{\circ} \mathrm{C}$ with a heating rate of $10^{\circ} \mathrm{C} / \mathrm{min}$ ute under a nitrogen condition. 


\subsubsection{Structural and morphological measurements}

The structural analysis of $\mathrm{PP} / \mathrm{GnPs}$ composites were conducted by means of X-ray diffraction (XRD) using Rigaku Miniflex $(\mathrm{Cu}-\mathrm{K} \alpha$ radiation, $\lambda=$ $1.54184 \AA$ ). The morphology of the composites was investigated by a scanning electron microscope (SEM) (Zeiss Leo 1550).

\subsubsection{Tensile strength measurement}

Dog bone tensile specimens were prepared by our injection moulding machine, and each specimen had a length of $75 \mathrm{~mm}$, a thickness of $2 \mathrm{~mm}$, and a parallel length of $30 \mathrm{~mm}$. Five samples were tested on a universal testing machine $(4.4 \mathrm{kN}$, eXpert 7603 , ADMET, USA) with a cross-head speed of $5 \mathrm{~mm} /$ minute at an ambient atmosphere in accordance to ASTM D638-14.

\subsubsection{Electrical conductivity measurement}

In-plane electrical conductivity $\left(\sigma_{\mathrm{I}}\right)$ was measured by a four-point probe method. Specimens were trimmed into dimensions of $15 \mathrm{~mm} \times 10 \mathrm{~mm} \times 2 \mathrm{~mm}$, and the polymer-rich surface was removed prior to measurement. The in-plane conductivity was calculated by Equation (1):

$\sigma_{\mathrm{I}}=\frac{1}{\rho}=\frac{1}{R \cdot t}=\left(\frac{\ln 2}{\pi \cdot t}\right) \frac{I}{V}\left[\mathrm{~S} \cdot \mathrm{cm}^{-1}\right]$

where $\rho$ is the electrical resistivity, $R$ is the electrical resistance, $t$ is the specimen thickness, $I$ is the applied current, and $V$ is the detected voltage drop. The four-point measurement setup was described elsewhere [27].

Through-plane conductivity $\left(\sigma_{\mathrm{T}}\right)$ was measured by placing the specimen in a house-built fixture under

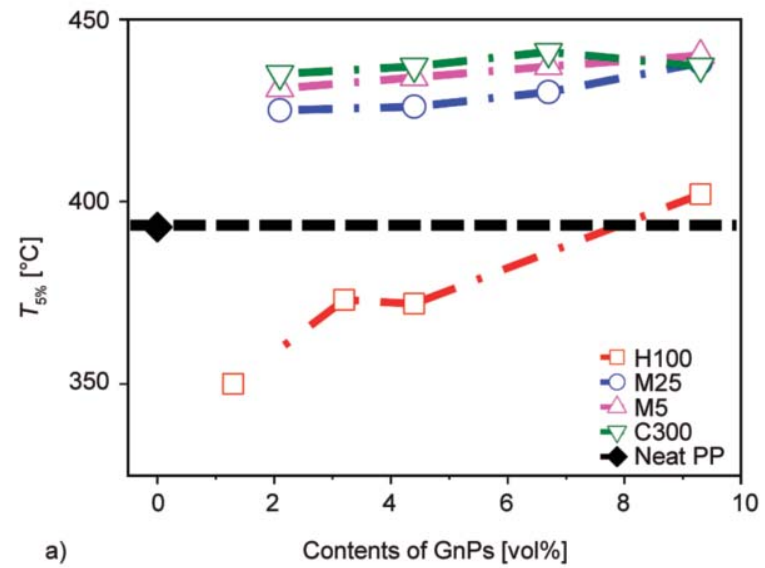

constant pressure. The samples were positioned between copper foil electrodes, and silver paste was employed to minimize the contact resistance between the samples and electrodes. The through-plane electrical conductivity was determined by Equation (2):

$\sigma_{\mathrm{T}}=\frac{t}{R \cdot A}\left[\mathrm{~S} \cdot \mathrm{cm}^{-1}\right]$

where $R$ is the electrical resistance, $t$ is the specimen thickness, and $A$ is the area of the sample. The schematic representation of through-plane setup was described elsewhere [27].

\section{Results and discussion}

\subsection{Thermal stability}

The thermal stability parameters estimated from TGA are provided in Table 3 , and $T_{5 \%}$ (5\% weight loss temperature) and $T_{\max }$ (the maximum mass loss temperature) are shown in Figure 2 with respect to the grade of each GnPs.

Figure 2 illustrates an improved thermal stability as the contents of the GnPs increase within the composite for all the grades. It is evident that the GnPs with a diameter less than $25 \mu \mathrm{m}$ (M25, M5, and C300) show superior effectiveness when compared to H100. While $T_{\max }$ is heightened with the addition of any grade of $\mathrm{GnPs}$, the composites incorporated with very large-sized $\mathrm{GnPs}$ (H100) exhibited inferior thermal stability at the initial stage of thermal decomposition in comparison to neat PP as indicated by $T_{5 \%}$ (Figure 2a). In general, GnPs are known to improve a thermal stability due to its barrier effect and removal of free-radicals initiating the decomposition of polymers [28, 29]. In addition, the dispersed GnPs sheets allow the thermal conduction and uniform

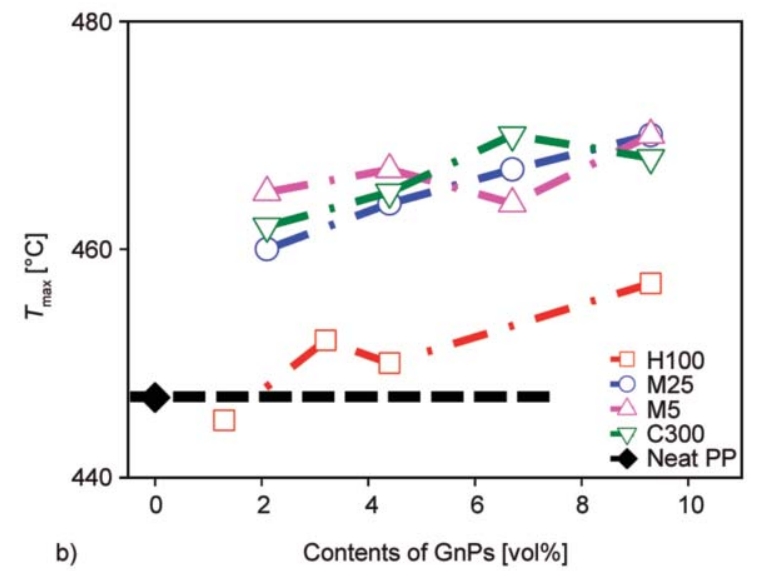

Figure 2. The variations of (a) $T_{5 \%}$ and (b) $T_{\max }$ with increasing amount of GnPs with respect to each grade. 
Table 3. Parameters extracted from TGA with respect to GnPs grades and their contents in the composites. The PP/H100 data were adapted from [27] with permission from Elsevier.

\begin{tabular}{|l|c|c|c|r|r|r|r|r|r|r|r|r|r|r|r|r|r|r|}
\hline & Neat PP & \multicolumn{4}{|c|}{ H100 } & \multicolumn{4}{c|}{ M25 } & \multicolumn{4}{c|}{ C300 } \\
\hline Contents of GnPs [vol\%] & 0.0 & 1.3 & 3.2 & 4.4 & 9.3 & 2.1 & 4.4 & 6.7 & 9.3 & 2.1 & 4.4 & 6.7 & 9.3 & 2.1 & 4.4 & 6.7 & 9.3 \\
\hline Contents of GnPs [wt\%] & 0.0 & 3.0 & 7.5 & 10.0 & 20.0 & 5.0 & 10.0 & 15.0 & 20.0 & 5.0 & 10.0 & 15.0 & 20.0 & 5.0 & 10.0 & 15.0 & 20.0 \\
\hline Residual amount $[\mathrm{wt} \%]$ & 0.0 & 3.1 & 6.9 & 9.5 & 18.9 & 4.5 & 10.4 & 14.2 & 19.5 & 4.1 & 8.5 & 13.6 & 19.2 & 5.9 & 8.9 & 14.7 & 19.3 \\
\hline$T_{5 \%} \%$ & 393 & 350 & 373 & 372 & 402 & 425 & 426 & 430 & 438 & 431 & 434 & 437 & 440 & 435 & 437 & 441 & 437 \\
\hline$\left.T_{\max }{ }^{\circ} \mathrm{C}\right]$ & 393 & 447 & 445 & 452 & 450 & 457 & 460 & 464 & 467 & 470 & 465 & 467 & 464 & 470 & 462 & 465 & 470 & 468 \\
\hline
\end{tabular}

distribution of heat spread in the polymer matrix, leading to an improved thermal stability. However, the SEM images show that $\mathrm{H} 100 \mathrm{GnPs}$ are highly restacked and agglomerated when compared to other small-sized GnPs (Figure 6), and this inferior dispersion of $\mathrm{H} 100$ could result in a reduced thermal stability. Since the advanced distribution of fillers within the matrix is achieved with smaller-sized GnPs, a significantly increased thermal stability is observed with these fillers such as M25, M5, and C300.

\subsection{Effect of GnPs on the crystallization of PP}

Crystallization $\left(T_{\mathrm{c}}\right)$ and melting temperatures $\left(T_{\mathrm{m}}\right)$ of PP composites with each grade of GnPs were measured by means of DSC and described as a function of GnPs contents in Figure 3. The crystallization parameters extracted from DSC are detailed in Table 4.
It is evident that the addition of GnPs considerably increases $T_{\mathrm{c}}$, indicating that the GnPs serve as nucleating agents [24]. This nucleating effect is amplified as the size of GnPs decreases. $T_{\mathrm{c}}$ increased by $14.3^{\circ} \mathrm{C}$ with the addition of 9 . vol $\%$ of $\mathrm{C} 300$ whereas the addition of $9.3 \mathrm{vol} \% \mathrm{H} 100$ only escalates $T_{\mathrm{c}}$ by $6.1{ }^{\circ} \mathrm{C}$. This is likely due to the well-dispersion and large surface area of C300. Since the GnPs fillers act as seeds for heterogeneous nucleation, crystallization can be facilitated at relatively higher temperatures when larger surface areas are available from small sized GnPs. While the crystallization temperature is largely influenced by addition of GnPs, the degree of crystallinity $\left(X_{\mathrm{c}}\right)$, calculated by melting enthalpy $\left(\Delta H_{\mathrm{m}}\right)$ measured from DSC, of the composites was not changed significantly with the addition of any size of GnPs as shown in Table 4.

Table 4. The crystallization parameters extracted from DSC. The PP/H100 data were adapted from [27] with permission from Elsevier.

\begin{tabular}{|c|c|c|c|c|c|c|c|c|c|c|c|c|c|c|c|c|c|}
\hline & \multirow{2}{*}{$\begin{array}{c}\text { Neat } \\
\text { PP }\end{array}$} & \multicolumn{4}{|c|}{$\begin{array}{c}\text { PP/H100 } \\
\text { [vol\%] }\end{array}$} & \multicolumn{4}{|c|}{$\begin{array}{c}\text { PP/M25 } \\
\text { [vol\%] }\end{array}$} & \multicolumn{4}{|c|}{$\begin{array}{l}\text { PP/M5 } \\
\text { [vol\%] }\end{array}$} & \multicolumn{4}{|c|}{$\begin{array}{c}\text { PP/C300 } \\
\text { [vol\%] }\end{array}$} \\
\hline & & 1.3 & 3.2 & 4.4 & 9.3 & 1 & 4.4 & 6.7 & 9 & 2.1 & 4.4 & 6.7 & & 2.1 & 4.4 & 6.7 & 9.3 \\
\hline $\begin{array}{ll}T_{\text {cry }} & {\left[{ }^{\circ} \mathrm{C}\right]} \\
\end{array}$ & & 27.1 & 127.9 & 28.6 & 9.6 & 8.2 & 29.6 & 131.5 & 133.1 & 29.7 & 131.9 & 33.6 & 34.9 & 132.6 & 135.6 & 137.2 & 37.8 \\
\hline$\left[{ }^{\circ} \mathrm{C}\right]$ & $x$ & 5 & 3.2 & 0 & 3 & .0 & .1 & 4.9 & 1 & .4 & 164.3 & 164.7 & .7 & 5.0 & 165.2 & 65.5 & 65 \\
\hline$\left[{ }^{\circ} \mathrm{C}\right]$ & & 36.5 & 3 & 4 & 33.7 & 35.8 & 3 & 33.4 & & 34.8 & 32. & 31. & 29 & 32.4 & 29 & 28.3 & 27.8 \\
\hline$\Delta H_{\text {cry }}\left[\mathrm{J} \cdot \mathrm{g}^{-1}\right]$ & 71.5 & 6.6 & 162.7 & 150.5 & 3.5 & 9.0 & 115.9 & 111.1 & 104.0 & 24.1 & 118.9 & 112.2 & 105.4 & 122.9 & 121.0 & 109.4 & 103. \\
\hline$\Delta H_{\mathrm{m}} \quad\left[\mathrm{J} \cdot \mathrm{g}^{-1}\right]$ & 24.8 & 2.5 & 117.3 & 113.1 & 100.6 & 23.1 & 116.4 & 112.3 & 105.7 & 122.0 & 116.2 & 110.7 & 105.5 & 122.4 & 117.8 & 108.6 & 103.5 \\
\hline$[\%]$ & 60 & 60 & 60 & 60 & 59 & 62 & 62 & 63 & 63 & 62 & 62 & 62 & 62 & 62 & 62 & 61 & 61 \\
\hline
\end{tabular}
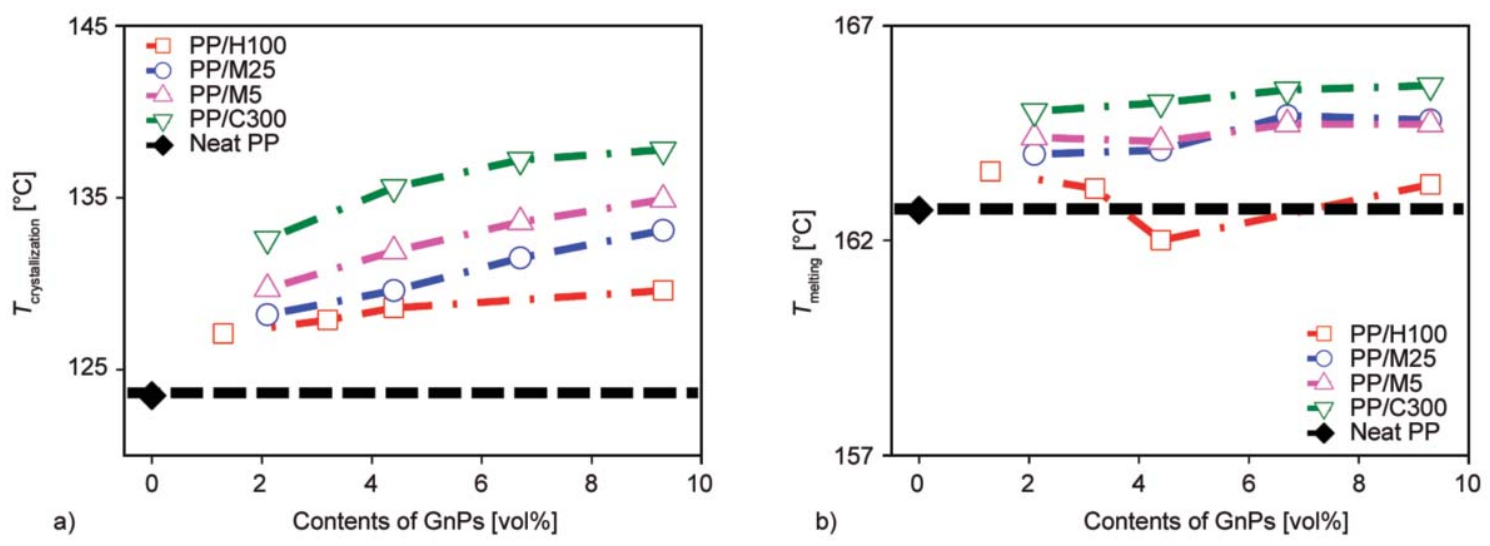

Figure 3. (a) Crystallization $\left(T_{\mathrm{c}}\right)$ and (b) melting temperatures $\left(T_{\mathrm{m}}\right)$ of PP/GnPs composites as a function of GnPs contents. 
The degree of crystallinity of neat PP was $60 \%$, and it increased up to $63 \%$ with $9.3 \mathrm{vol} \%$ of M $25 \mathrm{GnPs}$, and up to $62 \%$ with 9.3 vol\% of M5 GnPs. This enhancement is rather insignificant considering the amount of fillers incorporated into the PP matrix. Moreover, unlike the $T_{\mathrm{c}}, T_{\mathrm{m}}$ of composites does not deviate considerably from that of neat PP (Figure $3 b$ ). Addition of $9.3 \mathrm{vol} \%$ of $\mathrm{H} 100$ only increases $T_{\mathrm{m}}$ by $0.6^{\circ} \mathrm{C}$, and only $2.9^{\circ} \mathrm{C}$ rises with 9.3 vol $\%$ of $\mathrm{C} 300$. The lesser degree of variation in $T_{\mathrm{m}}$ indicates that the crystal types of PP remain invariant with the addition of all the different grades of the GnPs. $T_{\mathrm{m}}$ is largely dependent upon the forms of crystals. For instance, $\alpha$-crystals show a melting point around $\sim 165^{\circ} \mathrm{C}$ and $\beta$-crystals around $150-160^{\circ} \mathrm{C}$, respectively [30]. In the XRD analysis below (Figure 4 ), $\beta$-crystals are observed from the composites with H100, M25, and M5, but it can be seen that the amount of $\beta$-crystals formed is insignificant and hence does not affect $T_{\mathrm{m}}$. The investigation on crystallization of PP by means of XRD illustrates that neat PP exhibits five main
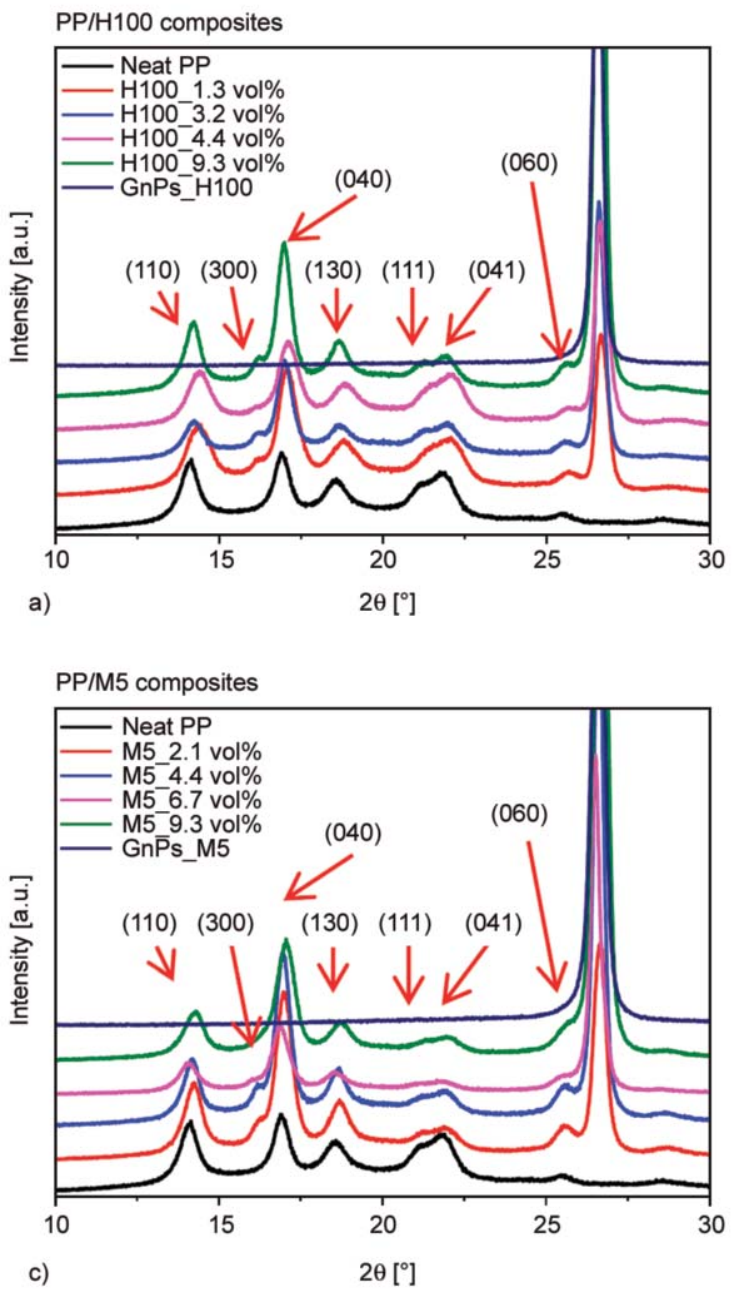

peaks at $14.08,16.95,18.5,21.2$, and $21.85^{\circ}$, which are responsible for (110), (040), (130), (111), and (041) of $\alpha$-crystals, respectively. Upon addition of GnPs, (040) plane at $16.95^{\circ}$ become significantly dominant, and the growth of the (060) plane peak is also observed. Further, the (300) plane of $\beta$-crystals also appeared for the composites incorporated with H100, M25, and M5. It should be noted that all the planes that showed significant peak growth with the presence of GnPs are in the general form of $(00 x)$ type, which is crystallographically in line with the GnPs (002) plane. It was shown that the GnPs may serve as a nucleation site and the nucleation begins around the GnPs $[24,31]$. When this occurs, it is possible that the PP chains can exhibit epitaxial growth on GnPs as $c$-axis of GnPs is merged with $b$-axis of $\mathrm{PP}$, indicating that (002) plane of GnPs is matched with (040) plane of PP. Similar phenomena were also reported in several other studies [13, 31, 32].

The appearance of $\beta$-crystals is not observed with the composites with $\mathrm{C} 300$, and this could be due to
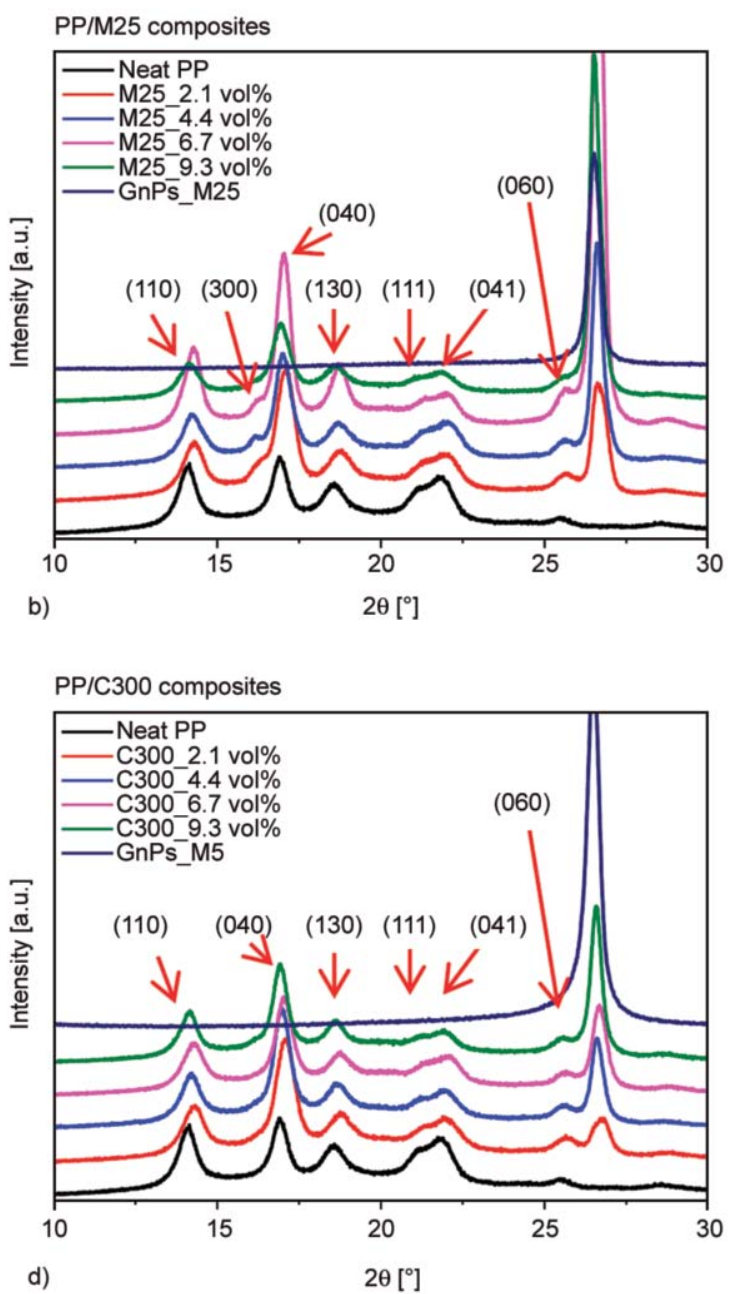

Figure 4. XRD curves of neat PP and PP composites compounded with (a) H100, (b) M25, (c) M5, and (d) C300, respectively. Figure $4 \mathrm{a}$ is adapted from [25] with permission from. 
the saturation effect associated with the small size of C300. When the size of GnPs is small, the greater number of GnPs particles will be present per unit volume when compared to larger-sized GnPs for the same loading. In this case, there might not be enough polymer chains that can orient and align along with all the GnPs particles when a large amount of GnPs within the composite is present. Kalaitzidou et al. [31] showed that this saturation occurred with only $1 \mathrm{vol} \%$ of GnPs with sheet size of $1 \mu \mathrm{m}$. The saturation effect diminishes as the size of GnPs increase, and the particular plane induced by GnPs can be observed with the high contents of GnPs. For example, the (300) plane was observed from PP/M5 composites with 4.4 vol\% and PP/M25 composites with 6.7 vol\%, respectively, and the (300) plane detected from all the PP/H100 composites with up to 9.3 vol\%. This saturation was also observed from PP composites incorporated with carbon nanotubes [33].

It has been known that $\beta$-crystals of PP give enhanced impact strength [34]. Since GnPs promote the formation of $\beta$-crystals of PP, the impact strength will increase with the addition of GnPs and the highest

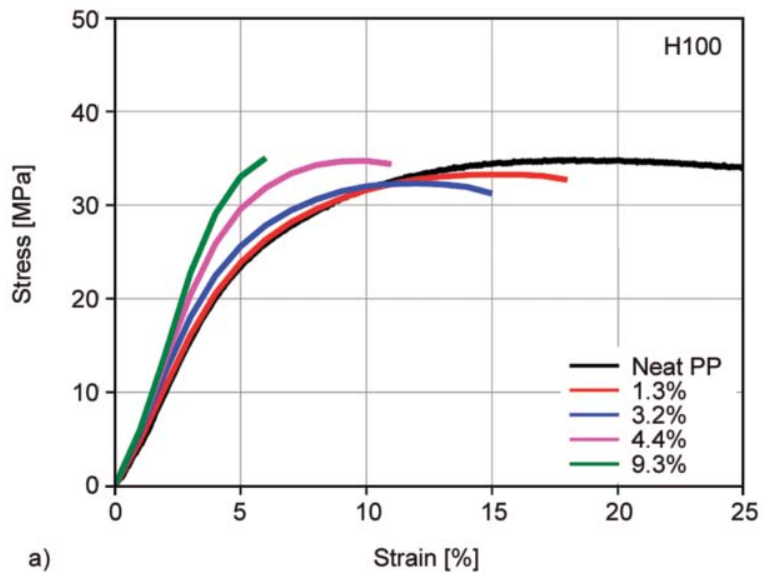

a)

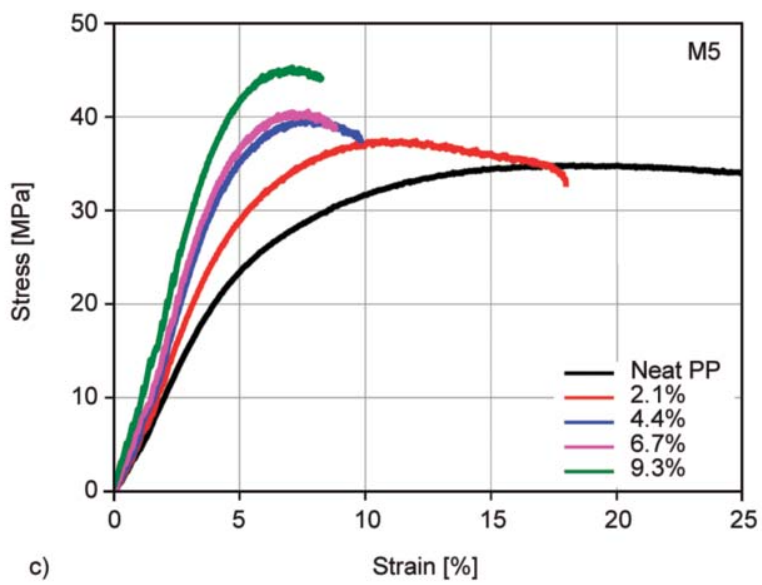

impact strength will be obtained at a GnPs' loading that saturates the $\beta$-crystal formation. Therefore, the particular GnPs' loading that shows the maximum impact strength will vary with different sizes of GnPs due to the saturation effect. A trend such as this has been observed elsewhere as well [35].

\subsection{Tensile strength}

Tensile strength and the tensile modulus were determined as a function of GnPs contents [vol\%] within the composites. The stress-strain curves of all the composites are described in Figure 5 with extracted parameters detailed in Table 5. Overall, tensile strength and modulus were consistently enhanced as the amount of GnPs incorporated increased except for the composites processed with $\mathrm{H} 100$. For the $\mathrm{PP} / \mathrm{H} 100$ composites, the tensile modulus was significantly enhanced while the tensile stress failed to show a considerable improvement. However, both tensile strength and tensile moduli were improved for all the composites incorporated with M25, M5, and C300, respectively. The failure of increasing tensile strength with $\mathrm{H} 100$ can be attributed to inferior interfacial
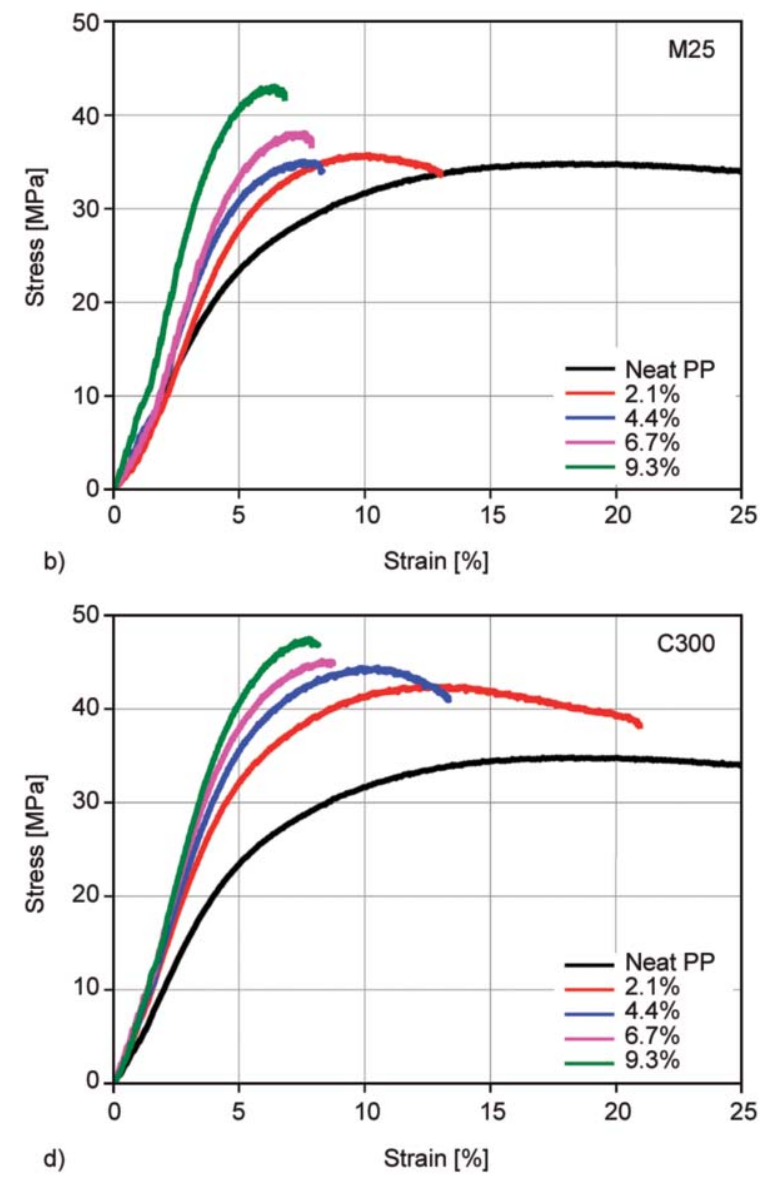

Figure 5. The representative stress-strain curves of PP composites incorporated with (a) H100, (b) M25, (c) M5, and (d) C300, respectively. 
Table 5. Tensile parameters extracted from the stress-strain curve with respect to GnPs grades and their contents in the composites.

\begin{tabular}{|c|c|c|c|c|c|c|c|c|c|c|c|c|c|c|c|c|c|}
\hline & Neat PP & \multicolumn{4}{|c|}{ H100 } & \multicolumn{4}{|c|}{ M25 } & \multicolumn{4}{|c|}{ M5 } & \multicolumn{4}{|c|}{$\mathbf{C 3 0 0}$} \\
\hline Contents of GnPs [vol\%] & 0.0 & 1.3 & 3.2 & 4.4 & 9.3 & 2.1 & 4.4 & 6.7 & 9.3 & 2.1 & 4.4 & 6.7 & 9.3 & 2.1 & 4.4 & 6.7 & 9.3 \\
\hline Tensile strength $\quad[\mathrm{MPa}]$ & $\begin{array}{l}\stackrel{+}{0} \\
+ \\
+ \\
\infty \\
\dot{m}\end{array}$ & 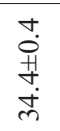 & 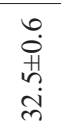 & $\begin{array}{l}\stackrel{a}{0} \\
\stackrel{+}{1} \\
\stackrel{n}{+} \\
\dot{m}\end{array}$ & $\begin{array}{l}\stackrel{\nabla}{+} \\
\dot{H} \\
\stackrel{m}{+}\end{array}$ & $\begin{array}{l}r \\
\dot{0} \\
\text { H } \\
\dot{n} \\
\dot{m}\end{array}$ & 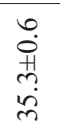 & 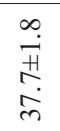 & $\begin{array}{l}\stackrel{\sigma}{\vec{H}} \\
\underset{\dot{\sigma}}{\dot{\sigma}}\end{array}$ & $\begin{array}{l}+\dot{0} \\
\stackrel{+}{1} \\
\stackrel{n}{n} \\
m\end{array}$ & $\begin{array}{l}\text { ت̇ } \\
\text { Hु } \\
\text { mे }\end{array}$ & $\begin{array}{l}0 \\
\text { H. } \\
\\
\stackrel{+}{+}\end{array}$ & $\begin{array}{l}\text { ․ } \\
\text { Hु } \\
\dot{q}\end{array}$ & $\begin{array}{l}\stackrel{r}{+} \\
\stackrel{+}{\circ} \\
\dot{q}\end{array}$ & $\begin{array}{l}0 \\
\dot{H} \\
\infty \\
\dot{\sigma}\end{array}$ & \begin{tabular}{l}
0 \\
$\dot{H}$ \\
\\
\cline { 1 - 1 }
\end{tabular} & $\begin{array}{l}\infty \\
\infty \\
0 \\
+ \\
+ \\
0 \\
\dot{+}\end{array}$ \\
\hline Tensile modulus [MPa] & $\frac{\stackrel{D}{H}}{\stackrel{\forall}{*}}$ & 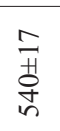 & $\begin{array}{l}\stackrel{a}{+} \\
\stackrel{+}{i} \\
\stackrel{b}{n}\end{array}$ & $\begin{array}{l}n \\
n \\
0 \\
0\end{array}$ & $\begin{array}{l}n \\
\text { ñ } \\
0 \\
0 \\
0\end{array}$ & $\begin{array}{l}\infty \\
\infty \\
+ \\
\stackrel{+}{+} \\
\text { in }\end{array}$ & 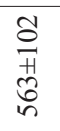 & 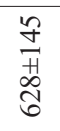 & $\begin{array}{l}0 \\
+ \\
+1 \\
\infty \\
\infty\end{array}$ & 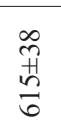 & 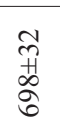 & $\begin{array}{l}\stackrel{0}{2} \\
\stackrel{1}{2} \\
\stackrel{2}{2}\end{array}$ & $\begin{array}{l}\stackrel{+}{n} \\
\stackrel{+}{ \pm} \\
\infty\end{array}$ & $\begin{array}{l}n \\
\tilde{n} \\
\hat{\sigma}\end{array}$ & $\underset{⿱}{\stackrel{+}{H}}$ & $\begin{array}{l}\stackrel{+}{ \pm} \\
\stackrel{+}{+}\end{array}$ & 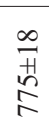 \\
\hline Elongation at break $[\%]$ & 908 & 17 & 15 & 12 & 1 & 13 & 10 & 9 & t & 18 & 10 & 9 & 0 & 21 & 14 & 9 & 8 \\
\hline
\end{tabular}

bonding between the polymer matrix and filler, largely caused by agglomeration, and thereby preventing the composites from achieving high degree of dispersion. Further, the morphology of $\mathrm{H} 100$ has been changed from platelets to spherical shapes as seen in Figure 6a, which can also cause adverse influences on reinforcement.

The improvement of tensile strength was most effective with the use of C300 grade of GnPs (Table 6). The smaller the size of the GnPs, the greater the efficiency of reinforcement was obtained. The addition of only $2.1 \mathrm{vol} \%$ of $\mathrm{C} 300$ resulted in the obtainment

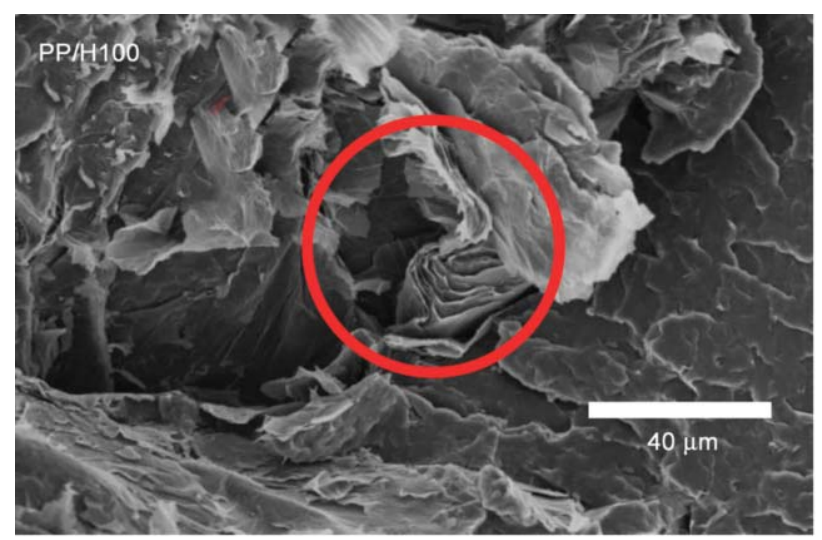

a)

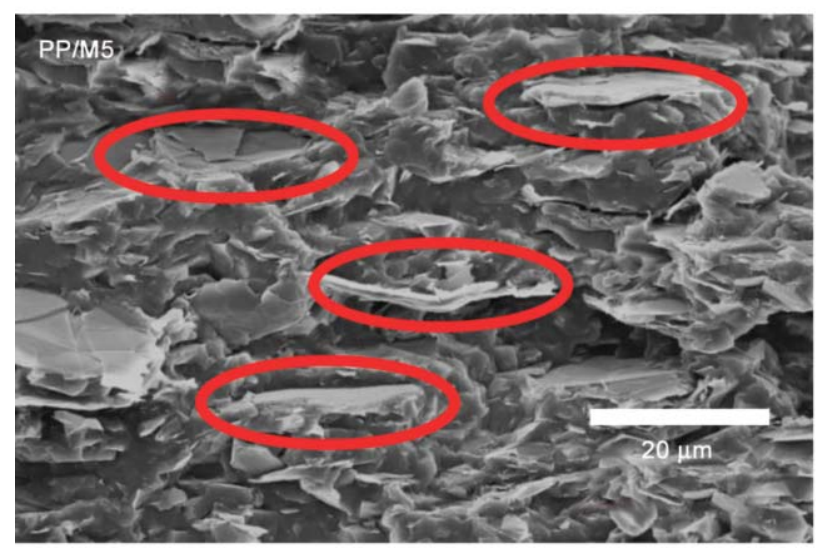

c) of a tensile strength greater than $40 \mathrm{MPa}$, which is a $17.5 \%$ of improvement from neat PP. Also, a $28.3 \%$ enhancement for tensile modulus was observed with the incorporation of $2.1 \mathrm{vol} \%$ of $\mathrm{C} 300$ (Table 6). It has been reported that a more significant reinforcement can be achieved with a reduced size of GnPs [15], and the mechanical property enhancement is inversely proportional to the size of the filler in many studies $[36,37]$. This could be due to increased surface areas that expedite efficient stress transfer between polymer matrix and fillers [38]. An increased surface area of fillers also provides a

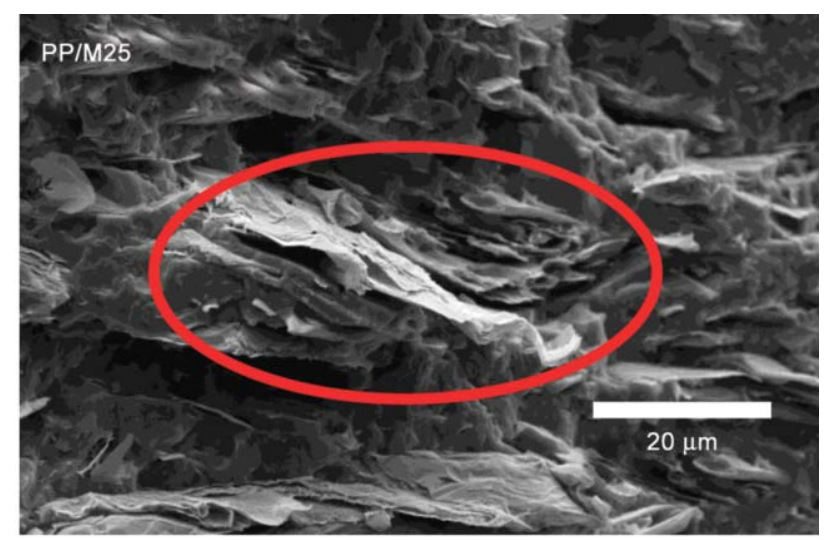

b)

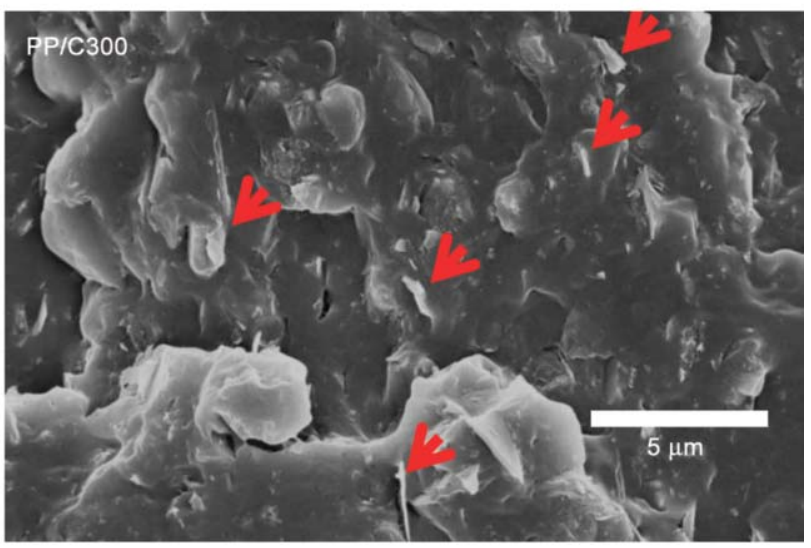

d)

Figure 6. The SEM images for PP/GnPs composites with (a) H100, (b) M25, (c) M5, and (d) C300, respectively. GnPs are indicated by circles or arrows in red. 
Table 6. Percentage improvement [\%] of tensile strength and tensile modulus of $\mathrm{PP} / \mathrm{GnPs}$ composites.

\begin{tabular}{|c|c|c|c|c|c|c|c|c|}
\hline \multirow{2}{*}{$\begin{array}{c}\text { GnPs } \\
\text { [vol\%] }\end{array}$} & \multicolumn{3}{|c|}{$\begin{array}{c}\text { Tensile strength } \\
\text { [\% improvement] }\end{array}$} & \multicolumn{4}{c|}{$\begin{array}{c}\text { Tensile modulus } \\
\text { [\% improvement] }\end{array}$} \\
\cline { 2 - 9 } & H100 & M25 & M5 & C300 & H100 & M25 & M5 & C300 \\
\hline 0.0 & 0.0 & 0.0 & 0.0 & 0.0 & 0.0 & 0.0 & 0.0 & 0.0 \\
\hline 1.3 & -1.1 & - & - & - & 5.1 & - & - & - \\
\hline 2.1 & - & 2.6 & 7.8 & 17.5 & - & 11.7 & 19.6 & 28.3 \\
\hline 3.2 & -6.6 & - & - & - & 10.4 & - & - & - \\
\hline 4.4 & -0.9 & 1.4 & 13.8 & 25.9 & 18.7 & 9.5 & 35.9 & 41.5 \\
\hline 6.7 & - & 8.3 & 15.5 & 29.9 & - & 22.2 & 40.0 & 44.4 \\
\hline 9.3 & -1.4 & 19.5 & 25.3 & 33.0 & 28.4 & 52.9 & 59.1 & 50.9 \\
\hline
\end{tabular}

greater hindrance to crack propagation leading to an improved strength [15]. Moreover, the largest elongation at break for the loading of $2.1 \mathrm{vol} \%$ of GnPs was also interestingly obtained with $\mathrm{C} 300$. This could be indicative of a greater degree of dispersion and less agglomeration of $\mathrm{C} 300$ within the matrix, since affinity between PP and GnPs does not change with GnPs size. In addition, C300 and other grades of GnPs with a small sheet size did not suffer from bending or buckling as seen from Figure 6, which helps boost the reinforcement effects. Therefore, the efficient reinforcement with small-sized fillers can be attributed to the combined effects of better dispersion, less agglomeration, and retention of the original filler morphology within the polymer matrix.

\subsection{Electrical conductivity}

In-plane and through-plane electrical conductivities of each composite were measured and described in Figure 7 and 8. As the amount of GnPs fillers in the composite increases, the composite undergoes an abrupt insulator-conductor transition, and there exists a particular concentration where

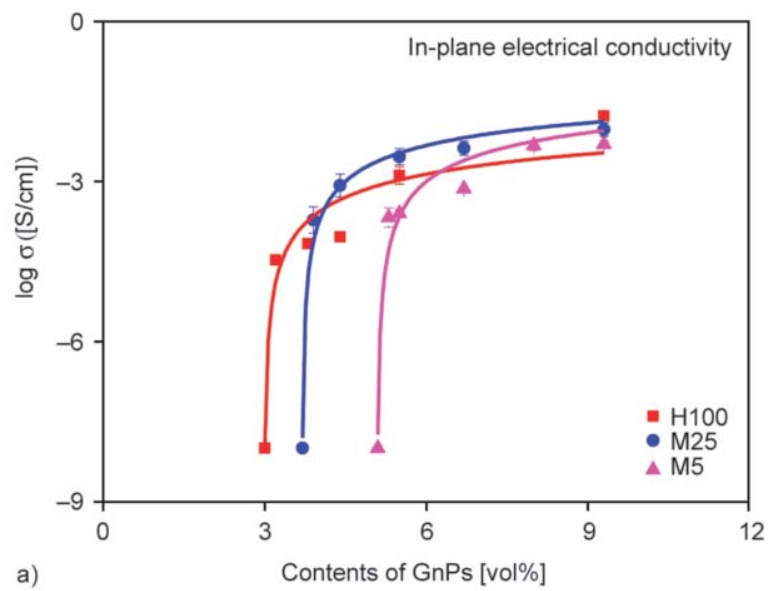

electrical conductivity exhibits a sudden increase. This specific concentration is commonly referred to as the percolation threshold [39]. The percolation threshold can be determined by fitting experimentally observed values to the power law as Equation (3):

$\sigma \sim\left(p-p_{\mathrm{c}}\right)^{\mathrm{s}}$

where $\sigma$ is the electrical conductivity of the composite, $p$ is the volumetric content of filler within composite, $p_{\mathrm{c}}$ is the particular percolation content, and $s$ is the critical exponent [39].

The estimated percolation thresholds for the composites with each GnPs grade are detailed in Table 7. It should be noted that the percolation threshold was not determined for the composites with $\mathrm{C} 300$ because the $\mathrm{C} 300$ composite was still insulating even with 9.29 vol\% of loading. A very low percolation threshold is achieved with the use of H100 when compared to other studies where GnPs were used as fillers and processed by conventional melt compounding as shown in Table 7 . H100 exhibited the percolation thresholds of $2.99 \mathrm{vol} \%$ for in-plane and 2.98 vol\% for through-plane conductivity, respectively. In fact, the percolation threshold from H100 was expected to be even lower, but the compromised morphology of fillers may have led to an increased percolation threshold. The percolation threshold for M25 and M5 was 3.66 and 5.05 vol\%, respectively. It is clearly observed that the percolation threshold increases as the sheet size of the GnPs reduces, and this trend confirms the well-known relationship between the aspect ratio of fillers and percolation threshold [40]. For the composites to become electrically conductive, the incorporated conducting fillers should

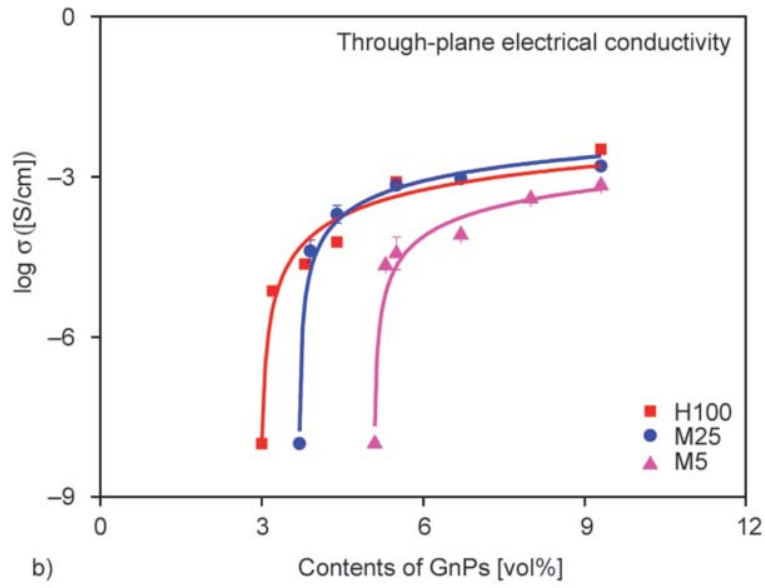

Figure 7. The (a) in-plane and (b) through-plane electrical conductivity of PP/GnPs composites with each grade of GnPs as a function of volume concentration of GnPs. 

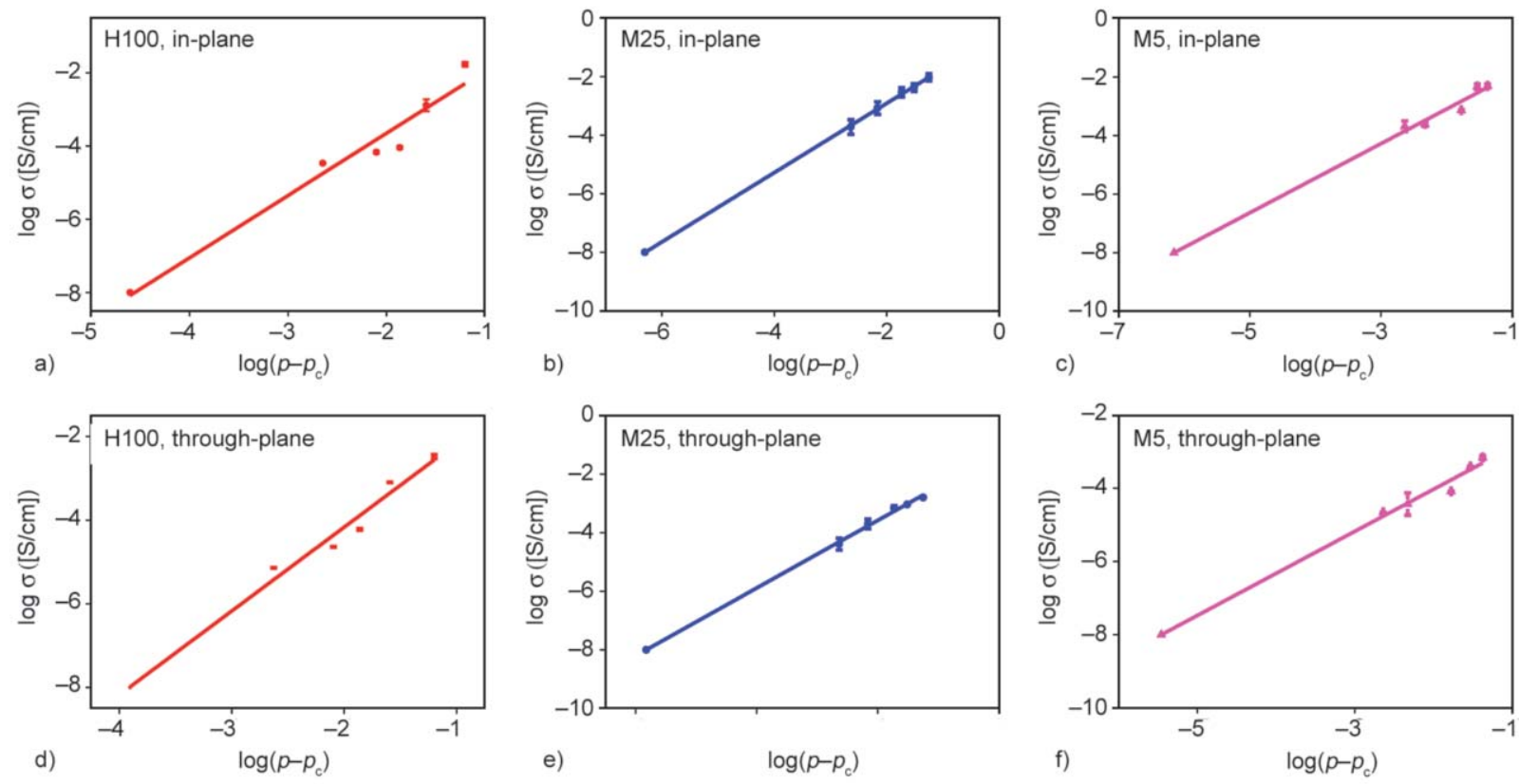

Figure 8. The log-log plot of electricalo conductivity $(\sigma)$ versus $\left(p-p_{c}\right)$ of in-plane conductivity for (a) H100, (b) M25, and through-plane for (d) H100, (e) M25, (f) M5, respectively.

make contact with one another and construct an interconnected pathway for electrons to travel. Using fillers with a large-sized sheet size, this conductive pathway will be readily formed with low concentration [41]. This is highly beneficial because a great processability and mechanical property can be retained. In order to further reduce percolation threshold, it is desired that the compromising of fillers be minimized by optimizing processing conditions or by employing other techniques that improve dispersion of fillers and introduce less shear force to compounding, such as solid state ball milling as seen in Table 7. Interestingly, while it is usual that a higher conductivity be observed with a large sheet size of fillers at the same loading of fillers, the composites with M25 exhibited higher conductivity at the GnPs loadings at around $4 \sim 5 \mathrm{vol} \%$ for both in-plane and throughplane. This could be due to the inferior state of dispersion caused by agglomeration of $\mathrm{H} 100$. As it was seen from Figure 6, H100 GnPs are considerably agglomerated, leading to reduction in lateral sheet size and a reduced number of dispersed particles per unit volume. This is very likely to produce a negative influence on the electrical conductivity. Nevertheless, the use of $\mathrm{H} 100$ is still beneficial for achieving a low percolation threshold which provides significant advantages for obtaining a great processability from a manufacturing point of view.

\section{Conclusions}

Four classes of GnPs (H100, M25, M5, and C300) with different physical properties were incorporated

Table 7. Comparison of reported percolation thresholds between this study and the literature.

\begin{tabular}{|c|c|c|c|c|c|}
\hline Ref. & Polymer matrix & $\begin{array}{c}\text { Filler } \\
\text { (diameter in } \mu \mathrm{m})\end{array}$ & \multirow{2}{*}{\multicolumn{2}{|c|}{$\begin{array}{c}\text { Percolation threshold } \\
6 \text { vol } \% \\
4 \text { vol } \%\end{array}$}} & Processing \\
\hline$[26]$ & Polypropylene & $\begin{array}{lr}x \mathrm{xGnP}-5 & (5) \\
\mathrm{xGnP}-10 & (10)\end{array}$ & & & Two roller mixing chamber \\
\hline$[25]$ & Polypropylene & $\mathrm{xGnP}-1$ & & $15 \mathrm{wt} \%$ & Twin screw extrusion \\
\hline$[42]$ & PE-LLD & $\mathrm{xGnP}-15$ & & $12 \mathrm{wt} \%$ & Solution compounding \\
\hline [43] & PE-HD & $x G n P-15$ & & $\begin{array}{l}-15 \text { vol } \% \\
-5 \text { vol } \%\end{array}$ & \begin{tabular}{|l|} 
Twin screw extrusion \\
Solid State Ball Milling
\end{tabular} \\
\hline This study & Polypropylene & $\begin{array}{lr}\text { xGnP H100 } & (\sim 150) \\
\text { xGnP M25 } & (\sim 25) \\
\text { xGnP M5 } & (\sim 5) \\
\text { xGnP C300 } & (\sim 2)\end{array}$ & \begin{tabular}{|} 
In-plane \\
$2.99 \mathrm{vol} \%$ \\
$3.66 \mathrm{vol} \%$ \\
$5.05 \mathrm{vol} \%$ \\
$>9.29 \mathrm{vol} \%$
\end{tabular} & \begin{tabular}{|r|} 
Through-plane \\
2.98 vol $\%$ \\
3.66 vol $\%$ \\
5.05 vol $\%$ \\
$>9.29$ vol $\%$
\end{tabular} & Twin screw extrusion \\
\hline
\end{tabular}


into PP to produce $\mathrm{PP} / \mathrm{GnPs}$ composites. The composites' thermal stability, the effect of GnPs on the crystallization behaviour of PP, tensile strength, and electrical conductivity were thoroughly studied. The PP composites incorporated with GnPs smaller than $25 \mu \mathrm{m}$ in diameter exhibited an improved thermal stability as indicated by $T_{5 \%}$ and $T_{\max }$. The addition of H100 into PP did not result in an enhanced thermal stability, especially at the initial stages of decomposition. This could be due to ultra large-sized GnPs with a high thermal conductivity that transfers heat across the composite, boosting the thermal decomposition throughout the entire composite simultaneously. The GnPs exert a considerable nucleating effect on the crystallization of PP by increasing $T_{\mathrm{c}}$ and by inducing particular planes, such as (300), (040), (060), which can be formulated by the epitaxial growth of polymer chains on the GnPs. The $X_{\mathrm{c}}$ was not significantly increased, however. The greatest efficiency in tensile strength reinforcement was achieved with the use of $\mathrm{C} 300$ due to the retention of original morphology and a high degree of dispersion with less agglomeration within the composite. The lowest percolation threshold was obtained when the GnPs with the largest sheet size (H100) was incorporated into a polymer matrix. It was shown from this study that a physical property of GnPs has a significant influence on the performance of the final composites. The GnPs with a smaller sheet size is recommended for the purpose of increasing thermal stability and mechanical strength while high electrical conductivity is readily achieved with large-sized GnPs. To achieve a composite with all-around performances, high dispersion of large-sized GnPs with retained original morphology should be accomplished with improved interfacial interactions.

\section{Acknowledgements}

This research was financially supported by the Natural Sciences and Engineering Research Council of Canada (NSERC).

\section{References}

[1] Rao C. N. R., Sood A. K., Subrahmanyam K. S., Govindaraj A.: Graphene: The new two-dimensional nanomaterial. Angewandte Chemie International Edition, 48, 7752-7777 (2009).

https://doi.org/10.1002/anie.200901678
[2] Geim A. K., Novoselov K. S.: The rise of graphene. Nature Materials, 6, 183-191 (2007).

https://doi.org/10.1038/nmat1849

[3] Geim A. K.: Graphene: Status and prospects. Science, 324, 1530-1534 (2009).

https://doi.org/10.1126/science. 1158877

[4] Dreyer D. R., Park S., Bielawski C. W., Ruoff R. S.: The chemistry of graphene oxide. Chemical Society Reviews, 39, 228-240 (2010). https://doi.org/10.1039/B917103G

[5] Singh V., Joung D., Zhai L., Das S., Khondaker S. I., Seal S.: Graphene based materials: Past, present and future. Progress in Materials Science, 56, 1178-1271 (2011). https://doi.org/10.1016/j.pmatsci.2011.03.003

[6] Kuilla T., Bhadra S., Yao D., Kim N. H., Bose S., Lee J. H.: Recent advances in graphene based polymer composites. Progress in Polymer Science, 35, 1350-1375 (2010).

https://doi.org/10.1016/j.progpolymsci.2010.07.005

[7] Das T. K., Prusty S.: Graphene-based polymer composites and their applications. Polymer-Plastics Technology and Engineering, 52, 319-331 (2013).

https://doi.org/10.1080/03602559.2012.751410

[8] Young R. J., Kinloch I. A., Gong L., Novoselov K. S.: The mechanics of graphene nanocomposites: A review. Composites Science and Technology, 72, 1459-1476 (2012).

https://doi.org/10.1016/j.compscitech.2012.05.005

[9] Potts J. R., Dreyer D. R., Bielawski C. W., Ruoff R. S.: Graphene-based polymer nanocomposites. Polymer, 52, 5-25 (2011). https://doi.org/10.1016/j.polymer.2010.11.042

[10] Via M. D., King J. A., Keith J. M., Miskioglu I., Cieslinski M. J., Anderson J. J., Bogucki G. R.: Tensile modulus modeling of carbon black/polycarbonate, carbon nanotube/polycarbonate, and exfoliated graphite nanoplatelet/polycarbonate composites. Journal of Applied Polymer Science, 124, 2269-2277 (2012).

https://doi.org/10.1002/app.35276

[11] Mayoral B., Harkin-Jones E., Khanam P. N., AlMaadeed M. A., Ouederni M., Hamilton A. R., Sun D.: Melt processing and characterisation of polyamide $6 /$ graphene nanoplatelet composites. RSC Advances, 5, 52395-52409 (2015). https://doi.org/10.1039/C5RA08509H

[12] Ahmadi-Moghadam B., Taheri F.: Effect of processing parameters on the structure and multi-functional performance of epoxy/GNP-nanocomposites. Journal of Materials Science, 49, 6180-6190 (2014). https://doi.org/10.1007/s10853-014-8332-y

[13] Kalantari B., Mohaddes Mojtahedi M. R., Sharif F., Rahbar R. S.: Flow-induced crystallization of polypropylene in the presence of graphene nanoplatelets and relevant mechanical properties in nanocompsoite fibres. Composites Part A: Applied Science and Manufacturing, 76, 203-214 (2015).

https://doi.org/10.1016/j.compositesa.2015.05.028 
[14] Galpaya D., Wang M., Liu M., Motta N., Waclawik E., Yan C.: Recent advances in fabrication and characterization of graphene-polymer nanocomposites. Graphene, 1, 30-49 (2012) https://doi.org/10.4236/graphene.2012.12005

[15] Kalaitzidou K., Fukushima H., Drzal L. T.: Mechanical properties and morphological characterization of exfoliated graphite-polypropylene nanocomposites. Composites Part A: Applied Science and Manufacturing, 38 , 1675-1682 (2007).

https://doi.org/10.1016/j.compositesa.2007.02.003

[16] An J-E., Jeon G. W., Jeong Y. G.: Preparation and properties of polypropylene nanocomposites reinforced with exfoliated graphene. Fibers and Polymers, 13, 507-514 (2012).

https://doi.org/10.1007/s12221-012-0507-z

[17] Liang J-Z., Du Q., Tsui G-C., Tang C.: Tensile properties of graphene nano-platelets reinforced polypropylene composites. Composites Part B: Engineering, 95, 166-171 (2016).

https://doi.org/10.1016/j.compositesb.2016.04.011

[18] Liang J. Z., Du Q., Wei L. Y., Tsui C. P., Tang C. Y., Law W. C. Zhang S. D.: Melt extrudate swell behavior of graphene nano-platelets filled-polypropylene composites. Polymer Testing, 45, 179-184 (2015). https://doi.org/10.1016/j.polymertesting.2015.06.007

[19] Inuwa I. M., Hassan A., Samsudin S. A., Kassim M. H. M., Jawaid M.: Mechanical and thermal properties of exfoliated graphite nanoplatelets reinforced polyethylene terephthalate/polypropylene composites. Polymer Composites, 35, 2029-2035 (2014).

https://doi.org/10.1002/pc.22863

[20] Jiang X., Drzal L. T.: Exploring the potential of exfoliated graphene nanoplatelets as the conductive filler in polymeric nanocomposites for bipolar plates. Journal of Power Sources, 218, 297-306 (2012).

https://doi.org/10.1016/j.jpowsour.2012.07.001

[21] Kalaitzidou K., Fukushima H., Miyagawa H., Drzal L. T.: Flexural and tensile moduli of polypropylene nanocomposites and comparison of experimental data to Halpin-Tsai and Tandon-Weng models. Polymer Engineering and Science, 47, 1796-1803 (2007).

https://doi.org/10.1002/pen.20879

[22] Chunhui S., Mu P., Runzhang Y.: The effect of particle size gradation of conductive fillers on the conductivity and the flexural strength of composite bipolar plate. International Journal of Hydrogen Energy, 33, 1035-1039 (2008).

https://doi.org/10.1016/j.jhydene.2007.11.013

[23] Bafana A. P., Yan X., Wei X., Patel M., Guo Z., Wei S., Wujcik E. K.: Polypropylene nanocomposites reinforced with low weight percent graphene nanoplatelets. Composites Part B: Engineering, 109, 101-107 (2017). https://doi.org/10.1016/j.compositesb.2016.10.048
[24] Pedrazzoli D., Pegoretti A., Kalaitzidou K.: Understanding the effect of silica nanoparticles and exfoliated graphite nanoplatelets on the crystallization behavior of isotactic polypropylene. Polymer Engineering and Science, 55, 672-680 (2015). https://doi.org/10.1002/pen.23941

[25] Park H. M., Kalaitzidou K., Fukushima H., Drzal L. T.: Exfoliated graphite nanoplatelet $(\mathrm{xGnP}) /$ polypropylene nanocomposites. in 'SPE Automotive and Composites Divisions $-7^{\text {th }}$ Annual Automotive Composites Conference and Exhibition. Troy, USA', Vol 1, 314-322 (2007).

[26] Kuvardina E. V., Novokshonova L. A., Lomakin S. M., Timan S. A., Tchmutin I. A.: Effect of the graphite nanoplatelet size on the mechanical, thermal, and electrical properties of polypropylene/exfoliated graphite nanocomposites. Journal of Applied Polymer Science, 128, 1417-1424 (2013).

https://doi.org/10.1002/app.38237

[27] Jun Y-S., Um J. G., Jiang G., Lui G., Yu A.: Ultra-large sized graphene nano-platelets (GnPs) incorporated polypropylene (PP)/GnPs composites engineered by melt compounding and its thermal, mechanical, and electrical properties. Composites Part B: Engineering, 133, 218-225 (2018).

https://doi.org/10.1016/j.compositesb.2017.09.028

[28] Zhao S., Chen F., Huang Y., Dong J-Y., Han C. C.: Crystallization behaviors in the isotactic polypropylene/ graphene composites. Polymer, 55, 4125-4135 (2014). https://doi.org/10.1016/j.polymer.2014.06.027

[29] Yang J., Huang Y., Lv Y., Zhao P., Yang Q., Li G.: The intrinsic thermal-oxidative stabilization effect of chemically reduced graphene oxide on polypropylene. Journal of Materials Chemistry A, 1, 11184-11191 (2013). https://doi.org/10.1039/c3ta11989k

[30] Xiao W., Wu P., Feng J.: Effect of $\beta$-nucleating agents on crystallization and melting behavior of isotactic polypropylene. Journal of Applied Polymer Science, 108, 3370-3379 (2008). https://doi.org/10.1002/app.27997

[31] Kalaitzidou K., Fukushima H., Askeland P., Drzal L. T.: The nucleating effect of exfoliated graphite nanoplatelets and their influence on the crystal structure and electrical conductivity of polypropylene nanocomposites. Journal of Materials Science, 43, 2895-2907 (2008). https://doi.org/10.1007/s10853-007-1876-3

[32] Ferrage E., Martin F., Boudet A., Petit S., Fourty G., Jouffret F., Micoud P., De Parseval P., Salvi S., Bourgerette C., Ferret J., Saint-Gerard Y., Buratto S., Fortune J. P.: Talc as nucleating agent of polypropylene: Morphology induced by lamellar particles addition and interface mineral-matrix modelization. Journal of Materials Science, 37, 1561-1573 (2002).

https://doi.org/10.1023/A:1014929121367 
[33] Valentini L., Biagiotti J., López-Manchado M. A., Santucci S., Kenny J. M.: Effects of carbon nanotubes on the crystallization behavior of polypropylene. Polymer Engineering and Science, 44, 303-311 (2004). https://doi.org/10.1002/pen.20028

[34] Huy T. A., Adhikari R., Lüpke T., Henning S., Michler G. H.: Molecular deformation mechanisms of isotactic polypropylene in $\alpha$ - and $\beta$-crystal forms by FTIR spectroscopy. Journal of Polymer Science Part B: Polymer Physics, 42, 4478-4488 (2004). https://doi.org/10.1002/polb.20117

[35] Kalaitzidou K.: Exfoliated graphite nanoplatelets as reinforcement for multifunctional polypropylene nanocomposites. $\mathrm{PhD}$ thesis. Michigan State University. East Lansing, USA (2006).

[36] Fu S-Y., Feng X-Q., Lauke B., Mai Y-W.: Effects of particle size, particle/matrix interface adhesion and particle loading on mechanical properties of particulatepolymer composites. Composites Part B: Engineering, 39, 933-961 (2008).

https://doi.org/10.1016/j.compositesb.2008.01.002

[37] Greer J. R., Oliver W. C., Nix W. D.: Size dependence of mechanical properties of gold at the micron scale in the absence of strain gradients. Acta Materialia, 53, 1821-1830 (2005).

https://doi.org/10.1016/j.actamat.2004.12.031
[38] Cadek M., Coleman J. N., Ryan K. P., Nicolosi V., Bister G., Fonseca A., Nagy J. B., Szostak K., Béguin F., Blau W. J.: Reinforcement of polymers with carbon nanotubes: The role of nanotube surface area. Nano Letters, 4, 353-356 (2004).

https://doi.org/10.1021/n1035009o

[39] Tjong S. C.: Polymer composites with carbonaceous nanofillers: Properties and applications. Wiley-VCH, Weinheim (2012). https://doi.org/10.1002/9783527648726

[40] Calvert P.: Nanotube composites: A recipe for strength. Nature, 399, 210-211 (1999). https://doi.org/10.1038/20326

[41] Jun Y-S., Sy S., Ahn W., Zarrin H., Rasen L., Tjandra R., Amoli B. M., Zhao B., Chiu G., Yu A.: Highly conductive interconnected graphene foam based polymer composite. Carbon, 95, 653-658 (2015). https://doi.org/10.1016/j.carbon.2015.08.079

[42] Kim S., Do I., Drzal L. T.: Multifunctional xGnP/ LLDPE nanocomposites prepared by solution compounding using various screw rotating systems. Macromolecular Materials and Engineering, 294, 196-205 (2009). https://doi.org/10.1002/mame.200800319

[43] Jiang X., Drzal L. T.: Reduction in percolation threshold of injection molded high-density polyethylene/exfoliated graphene nanoplatelets composites by solid state ball milling and solid state shear pulverization. Journal of Applied Polymer Science, 124, 525-535 (2012). https://doi.org/10.1002/app.34891 